\title{
Effects of flavonoids on expression of genes involved in cell cycle regulation and DNA replication in human fibroblasts
}

\author{
Marta Moskot $^{1}$ • Joanna Jakóbkiewicz-Banecka ${ }^{2}$ Elwira Smolińska ${ }^{2}$ • \\ Ewa Piotrowska ${ }^{2} \cdot$ Grzegorz Węgrzyn $^{2} \cdot$ Magdalena Gabig-Cimińska $^{1}$
}

Received: 16 January 2015/ Accepted: 16 May 2015/Published online: 24 May 2015

(c) The Author(s) 2015. This article is published with open access at Springerlink.com

\begin{abstract}
Flavonoids have been studied as potential agents in medicine for many years. Among them, genistein was found to be active in various biological systems, mainly in prevention of cancer. Our recent work supported the idea that genistein also impacts multiple cellular processes in healthy fibroblasts; however, its effects on cell cycle-related pathways remained to be elucidated. Thus, in this work, high throughput screening with microarrays coupled to real-time quantitative Reverse Transcription PCR analyses was employed to study the changes in expression of key genes associated with cell cycle regulation and/or DNA replication in response to genistein, kaempferol, daidzein, and mixtures of genistein and either kaempferol or daidzein. Among them, genistein was found as the most significantly modulating, in a time- and dosedependent manner, compound of activity of studied genes, whose products are involved in different phases of the cell cycle and/or in regulatory processes important for DNA replication and cell growth. It considerably reduced the efficiency of expression of genes coding for MCM2-7 and MCM10 helicases, as well as some other proteins involved in the $\mathrm{S}$ phase control. In addition, genistein caused cell cycle arrest in the G2/M phase, which was
\end{abstract}

Magdalena Gabig-Cimińska

m.gabig@biol.ug.edu.pl

1 Laboratory of Molecular Biology (affiliated with the University of Gdańsk), Institute of Biochemistry and Biophysics, Polish Academy of Sciences, Wita Stwosza 59, 80-308 Gdańsk, Poland

2 Department of Molecular Biology, University of Gdańsk, Wita Stwosza 59, 80-308 Gdańsk, Poland accompanied by activation of CDKNIA, CDKNIC, $C D K N 2 A, C D K N 2 B, C D K N 2 C$, and GADD45A genes, as well as down-regulation of several mRNAs specific for this stage, demonstrated by transcriptomic assessments. We believe that studies described in this paper will be helpful in elucidating molecular mechanisms of action of genistein as modulator of cell cycle and inhibitor of DNA replication in humans.

Keywords Flavonoids - Cell cycle regulation - DNA replication process $\cdot$ Gene expression profiling $\cdot$ Cell growth

\section{Introduction}

Compounds produced by one kind of organism (one species) can significantly influence physiology of other species. Interesting examples are plant-derived metabolites, which have various biological activities and can affect basic biological processes in humans [1]. In fact, such compounds can be taken by humans with food, which in turn has an impact on health condition of the human body. Examples of bioactive plant metabolites are flavonoids [2]. This group consists of compounds that are considered as therapeutic molecules for cancer, infections, and some genetic diseases, for example, cystic fibrosis and mucopolysaccharidoses [3-5]. Therefore, determining mechanisms of their biological activities is very important to assess safety of these compounds and to develop optimal therapeutic procedures. Interestingly, flavonoids can influence cell cycle and DNA metabolism, but detailed mechanisms of their actions are not completely understood [2]. Effects of plant metabolites, among them genistein, on cell cycle and DNA replication have been studied in the 
light of human health, especially prevention of cancer [611]. Genistein was found to inhibit cell division cycle and DNA replication in eukaryotic cells when used at sufficiently high concentrations $[12,13]$. It was suggested that such an action might be caused by blocking activity of topoisomerase [14-17]. Genistein was also shown to exhibit biological activity through inhibition of various kinases [14, 18].

Recently, in order to investigate more extensively the effects of genistein in cell culture models, we have used DNA microarrays to assess the global effects of this compound on RNA expression in fibroblasts obtained from a healthy adult donor [19]. These studies supported the idea that genistein impacts multiple cellular pathways; however, its specificity and effects on cell cycle-related pathways remained to be delineated. The cell cycle or cell division cycle is the series of events that takes place in a cell leading to its division and duplication. It is controlled by numerous mechanisms ensuring correct cell splitting. Elucidation of the global pattern of molecular changes caused by genistein in respect to cell proliferation and DNA replication is desired in the light of the complex nature of genistein's biological activity as well as its unique effects in various biological systems, above all in humans. We found this topic interesting in respect not only to genistein, but also to other flavonoids, kaempferol, and daidzein, likewise mixtures of genistein and either of them. We employed human cell line of fibroblasts, which should open new possibilities to assess cell cycle regulatory processes operating in normal, untransformed, cells. The use of a cell culture model that exhibits a finite proliferative capacity has the advantage of providing a controlled environment to study a wide variety of cellular phenomena. It has also the inherent limitation of isolating cells from the regulatory elements that might be provided by other types of cells. Among different cells types (such as glial cells, keratinocytes, vascular smooth muscle cells, lens cells, endothelial cells, lymphocytes, liver, and melanocytes), fibroblasts from normal individuals exhibit most limited replicative life-span in the culture and therefore remain a powerful tool for a variety of studies.

We assumed that such studies have to contribute to both extending our basic knowledge on the influence of flavonoids on human cell cycle and identifying potential adverse effects on these compounds (used in various therapies) in normal cells. To address these issues, we utilized transcriptomic approach, i.e., a microarray gene profiling and a real-time quantitative Reverse Transcription PCR (realtime qRT-PCR) to examine gene expression, as well as cell viability and cell cycle progression tests to study development of fibroblasts exposed to different concentrations of tested compounds.

\section{Materials and methods}

\section{Cell lines, culture media, supplements, and flavonoid solutions}

Human Dermal Fibroblasts, adult (HDFa) (Cascade Biologics, Portland, USA) were cultured in Dulbecco's modified Eagle's medium (DMEM, Sigma-Aldrich, Steinheim, Germany) supplemented with $10 \%$ fetal bovine serum (FBS) and $1 \%$ antibiotic/antimycotic solution (Sigma-Aldrich, Steinheim, Germany), at $37{ }^{\circ} \mathrm{C}$ and $5 \%$ $\mathrm{CO}_{2}$. Genistein was synthesized at the Pharmaceutical Research Institute (Warsaw, Poland), while kaempferol and daidzein were obtained from Sigma-Aldrich (Steinheim, Germany). Tested flavonoids were dissolved in dimethyl sulfoxide (DMSO) and added to cell cultures at the indicated final concentrations as determined in previous studies $[20,21]$. For experimental procedures, cells were plated at approximately $80 \%$ confluence. After overnight incubation, culture medium was replaced with fresh medium either flavonoid-free, containing DMSO at a final concentration of $0.05 \%$ (control, K), or the one supplemented with appropriate amount of tested flavonoids. The experimental treatment was 24 and $48 \mathrm{~h}$ period.

\section{RNA extraction}

Total RNA was extracted from cells using the High Pure RNA Isolation Kit (Roche Applied Science, Indianapolis, USA) following the manufacturer's instructions. The quality and quantity of each RNA sample was evaluated using the RNA 6000 Nano Assay on the Agilent 2100 Bioanalyser (Agilent Technologies Inc., USA).

\section{Microarray assays for mRNA analysis}

Whole genome microarray analysis of three biological replicates $(n)$ was performed using Illumina's Human HT12v4 Expression BeadChips (Illumina Inc., USA). The assay performance, data extraction, and statistical analysis were performed as previously described [19]. Gene Ontology analysis and data visualization were performed using the web tools GOrilla (http://cbl-gorilla.cs.technion.ac. il/) and REViGO (http://revigo.irb.hr/) restricting the output to biological process and cell compartment. Gene set enrichment analysis (GSEA) was performed on the upregulated and down-regulated gene lists, separately as previously described [22, 23]. A nominal $P$ value $<0.01$ and a false discovery rate (FDR) $<0.25$ were used to assess the significance of the enrichment scores. The microarray expression data used in this study have GEO accession numbers GSE34074 and GSE43692. 


\section{Real-time quantitative RT-PCR array for mRNA analysis}

Total RNA was retrotranscribed with Transcriptor FirstStrand cDNA Synthesis Kit (Roche Applied Science, Indianapolis, USA). Real-time qRT-PCR was carried out with Real-Time ready Custom Panel (cat no. 05532914001, config. no. 100064133; Roche Applied Science, Indianapolis, USA) and the LightCycler ${ }^{\circledR} 480$ Probes Master (Roche Applied Science, Indianapolis, USA) using the Light Cycler 480 II detection system (Roche). Expression values were normalized against three control genes $B 2 M$, $G A P D H$, and RPLPO of constant expression level. For both microarray and real-time qRT-PCR analyses, a fold change (FC) greater or equal to 1.3 and below 0.7 was considered as a relevant criterion for genes being significantly differentially expressed.

\section{Cytotoxicity and proliferation assay}

MTT (3-[4,5-dimethylthiazol-2-yl]-2,5-diphenyltetrazolium bromide) assay was performed to estimate cell growth and proliferation. Cells were plated in flat-bottomed 96-well plates and treated with 30,60 , and $100 \mu \mathrm{M}$ of genistein or $0.05 \%$ DMSO as control for $24,48,72 \mathrm{~h}$, and 7 days at $37{ }^{\circ} \mathrm{C}$. After incubation period, medium was replaced with RPMI (Sigma-Aldrich) supplemented with MTT $(1 \mathrm{mg} / \mathrm{ml})$ for another $4 \mathrm{~h}$. The purple formazan crystals were dissolved in $150 \mathrm{ml}$ DMSO, and absorbance was determined at $570 \mathrm{~nm}$ using Wallac 1420 Multilabel Counter (Perkin Elmer).

\section{Cell viability assessment}

$10^{5}$ fibroblasts were seeded in triplicate in 6-well plates. The medium was changed the following day and supplemented with 30,60 , and $100 \mu \mathrm{M}$ of genistein or $0.05 \%$ DMSO as control for 24,48 , and $72 \mathrm{~h}$. Cells were counted, and viability was estimated by MUSE $^{\circledR}$ Cell Analyzer (Merck Millipore, Germany) and Muse ${ }^{\circledR}$ Count \& Viability Assay Kit (Merck Millipore, Germany). An average of 2000 cells was analyzed for each condition.

\section{Fibroblast migration assay}

To study the effect of genistein on cell migration, $5 \times 10^{4}$ fibroblasts were seeded in triplicate in 6-well plates. The dishes were incubated at $37{ }^{\circ} \mathrm{C}$ until cells reach $100 \%$ confluence to form a monolayer. A pipet tip was used to create a scratch of the cell monolayer, after that the plate was washed once and replaced with the desired medium, i.e., supplemented with 30,60 , and $100 \mu \mathrm{M}$ of genistein or $0.05 \%$ DMSO as control. The rate of cell migration was determined for the cells by measuring the distance traveled during the desired time frame of incubation, i.e., at $0,6,12$, 18 , and $24 \mathrm{~h}$.

\section{Cell cycle assay}

The effect of flavonoids on cell cycle was evaluated by seeding fibroblasts into 6-well plates at a density of $1 \times 10^{4}$ cells per well. After $24 \mathrm{~h}$, the medium was replaced with fresh one containing flavonoids. Cell cycle phase was determined by MUSE ${ }^{\circledR}$ Cell Analyzer (Merck Millipore, Germany) using a Muse ${ }^{\circledR}$ Cell Cycle Assay Kit (Merck Millipore, Germany) according to the manufacturer's instructions. An average of 10,000 cells was analyzed for each condition. Triplicate independent experiments were conducted.

\section{Results}

\section{Microarray expression analysis of cell cycle regulation and/or DNA replication-related genes}

Whole genome microarray analysis of gene expression was performed in our prior experiments with human fibroblasts treated with genistein, daidzein, kaempferol, and their mixtures ([19]; GEO accession numbers GSE34074 and GSE43692). In this work, cell cycle and/or DNA replication-related genes (retrieved from: GO:0000278-mitotic cell cycle; KEGG:hsa04110 — cell cycle; GO:0055133DNA replication; KEGG:hsa03030-DNA replication) were filtered based on desired patterns of expression, upand down-regulation at various experimental conditions. 157 genes (42 up- and 115 down-regulated) among 213 belonging to cell cycle and/or DNA replication transcripts revealed modulated activity upon at least a single type of experimental conditions (Table 1).

Among the tested flavonoids, genistein, kaempferol, and their mixture belonged to the treatment conditions responsible for the highest number of genes with modulated expression in fibroblasts after both 24 and $48 \mathrm{~h}$ (Table 2). In total, 77, 60, and 23 transcripts for $24 \mathrm{~h}$ and 68, 95, and 91 for $48 \mathrm{~h}$ handling with $100 \mu \mathrm{M}$ genistein, $100 \mu \mathrm{M}$ kaempferol, and mix of genistein with kaempferol (30 $\mu \mathrm{M}$ each), respectively, were affected.

Interpretation of biological meaning of defining cell cycle- and DNA replication-associated gene sets was performed by GSEA analysis. The results showed a significant enrichment among these genes regulated by genistein, kaempferol, and genistein-kaempferol mix (Fig. 1), with normalized Enrichment Score stronger than in the case of daidzein and genistein-daidzein treatment (data not shown). 
Table 1 Number of genes related to cell cycle and/or DNA replication process with expression modulated in $\mathrm{HDFa}$ cells by tested flavonoids or their mixtures at least in one experimental condition with respect to total number of genes key to cell cycle and/ or DNA replication regulation analyzed with microarrays

\begin{tabular}{|c|c|c|c|}
\hline \multirow[t]{2}{*}{ Genes } & \multicolumn{3}{|l|}{ Biological process } \\
\hline & $\begin{array}{l}\text { Cell cycle and/or replication } \\
\text { No. of genes }\end{array}$ & Cell cycle & Replication \\
\hline Total (regulated and un-regulated) & 213 & 128 & 112 \\
\hline Regulated & 157 & 93 & 86 \\
\hline Up-regulated & 42 & 29 & 17 \\
\hline Down-regulated & 115 & 64 & 69 \\
\hline
\end{tabular}

The fold change of gene expression ratios was $\geq 1.3$ and $\leq 0.7$, with a $P$ value $<0.05$ corrected by false discovery rate, and $n \geq 3$ were considered for flavonoid-treated cells against DMSO-treated samples

Table 2 Number of genes altered as a function of the treatment type

\begin{tabular}{|c|c|c|c|c|c|c|c|c|c|c|c|c|c|c|c|c|c|c|c|c|}
\hline \multirow{6}{*}{$\begin{array}{l}\text { Gene expression } \\
\text { modulation }\end{array}$} & \multicolumn{20}{|c|}{ No. of genes } \\
\hline & \multicolumn{6}{|c|}{ Genistein } & \multicolumn{6}{|c|}{ Kaempferol } & \multicolumn{2}{|c|}{ Genistein+kaempferol } & \multicolumn{4}{|c|}{ Daidzein } & \multicolumn{2}{|c|}{ Genistein+daidzeiı } \\
\hline & \multicolumn{20}{|c|}{ Concentration $(\mu \mathrm{M})$} \\
\hline & \multicolumn{2}{|l|}{30} & \multicolumn{2}{|l|}{60} & \multicolumn{2}{|c|}{100} & \multicolumn{2}{|l|}{30} & \multicolumn{2}{|l|}{60} & \multicolumn{2}{|c|}{100} & \multicolumn{2}{|c|}{$30+30$} & \multicolumn{2}{|c|}{60} & \multicolumn{2}{|c|}{100} & \multicolumn{2}{|c|}{$30+30$} \\
\hline & \multicolumn{20}{|c|}{ Time of exposure (h) } \\
\hline & 24 & 48 & 24 & 48 & 24 & 48 & 24 & 48 & 24 & 48 & 24 & 48 & 24 & 48 & 24 & 48 & 24 & 48 & 24 & 48 \\
\hline In sum & 17 & 29 & 60 & 50 & 77 & 68 & 69 & 82 & 43 & 91 & 60 & 95 & 23 & 91 & 17 & 84 & 12 & 55 & 6 & 65 \\
\hline Up-regulation & 2 & 2 & 7 & 7 & 16 & 16 & 9 & 12 & 7 & 16 & 14 & 18 & 13 & 17 & 6 & 10 & 10 & 13 & 5 & 20 \\
\hline Down-regulation & 15 & 27 & 53 & 43 & 61 & 52 & 60 & 70 & 36 & 75 & 46 & 77 & 10 & 74 & 11 & 74 & 2 & 42 & 1 & 45 \\
\hline
\end{tabular}

Genes key to cell cycle and DNA replication regulation with expression modulated in HDFa cells upon flavonoid treatment were obtained from microarray analysis against DMSO-treated samples

Alterations in mRNA level of selected genes were considered as $0.7 \geq \mathrm{FC} \geq 1.3$, with a $P$ value $<0.05$, and $n \geq 3$

Furthermore, the analysis of 'Cellular Compartment' as well as 'Biological Processes' terms revealed that among all tested conditions, treatment respectively with genistein, kaempferol, and genistein-kaempferol mix altered significantly the expression of cell cycle- and DNA replication-related genes (Fig. 2). These enrichments for these categories were noticeably stronger than those observed when daidzein or genistein-daidzein mix were applied (data not shown).

\section{Real-time qRT-PCR expression analysis of selected genes}

Relative activity of 44 cell cycle and/or DNA replicationrelated genes, selected previously in the course of microarray analysis, in HDFa fibroblasts treated for $24 \mathrm{~h}$ with $100 \mu \mathrm{M}$ genistein were examined by real-time qRT-PCR (Table 3). A custom-made human cell cycle profiler PCR array plate was utilized to assess the expression levels of particular genes and to validate microarray data. We confirmed considerable down-regulation of expression of most genes tested, with only four activated transcripts $(C D K N 1 A, C D K N 1 C, C D K N 2 B$, and GADD45A) in response to $100 \mu \mathrm{M}$ genistein after $24 \mathrm{~h}$ period of its action. Among these 44 genes, either up or down-regulated, three, i.e., $M C M 8, C D K N 2 A$, and $C D K N 2 C$ gave different responses in both DNA microarray and real-time qRT-PCR analyses.

\section{Cytotoxicity of genistein and its effect on migration and growth of fibroblasts and cell cycle progression}

To investigate the cytotoxicity effect of genistein, we measured metabolic activity of $\mathrm{HDFa}$ cells treated with different concentrations $(30,60$, and $100 \mu \mathrm{M})$ of genistein for different periods of time (24, 48 , and $72 \mathrm{~h})$. The cytotoxicity assessed as LC25, 50, and 75 is described in Table 4 . The lethal concentration values were $>100 \mu \mathrm{M}$, except for LC25 values of 59 and $41 \mu \mathrm{M}$ genistein after 48- 


\section{A GEN24h}

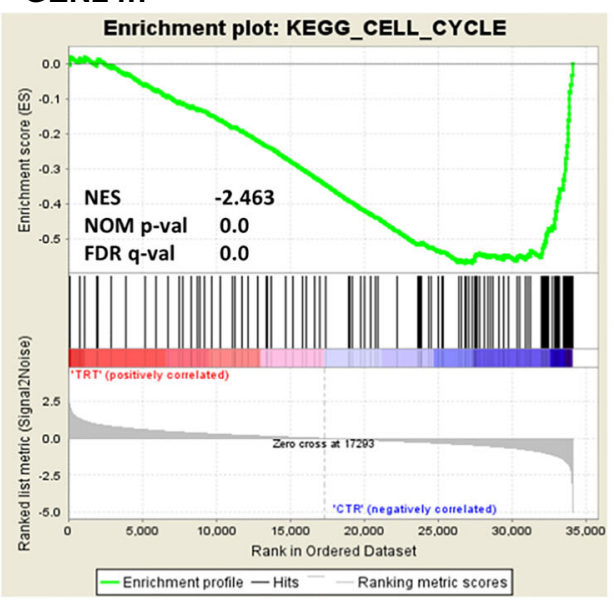

KAEM24h

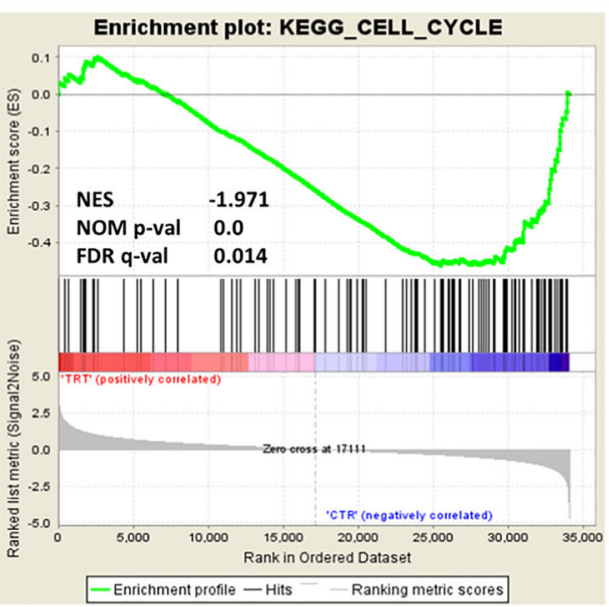

GEN+KAEM24h

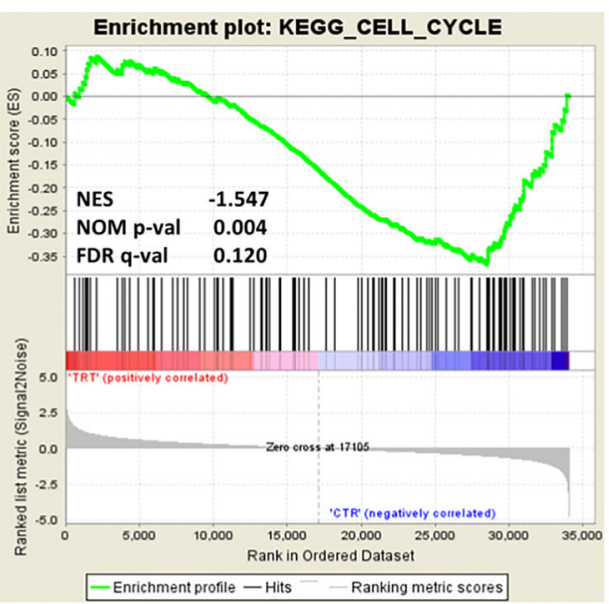

Fig. 1 GSEA analysis of cell cycle-related (a) and DNA replication regulation (b) gene sets enriched among genes up- and downregulated by $100 \mu \mathrm{M}$ genistein (GEN), $100 \mu \mathrm{M}$ kaempferol (KAEM), and mixture of them (GEN + KAEM) at $30 \mu \mathrm{M}$ each, for 24 and $48 \mathrm{~h}$ in HDFa fibroblasts. Graphs show the enrichment plots generated by GSEA analysis of ranked gene expression data (left

\section{GEN48h}

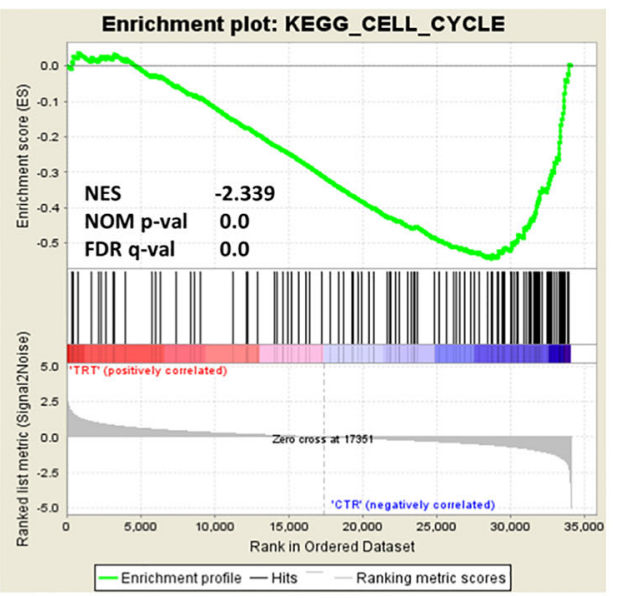

\section{KAEM48h}

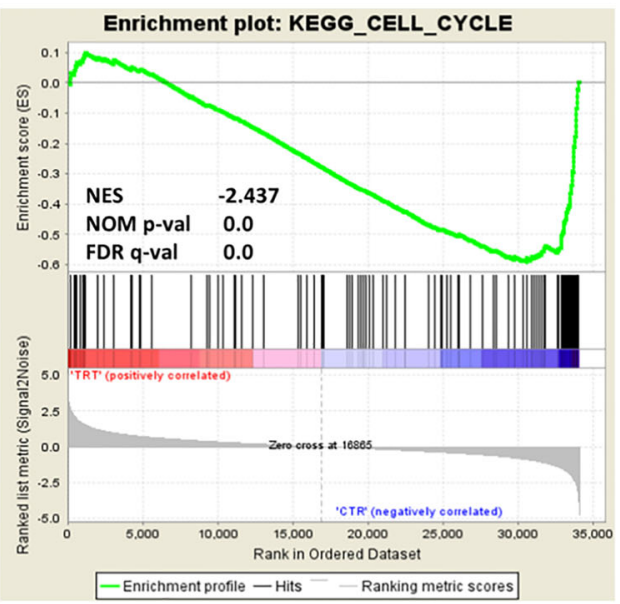

\section{GEN+KAEM48h}

Enrichment plot: KEGG_CELL_CYCLE

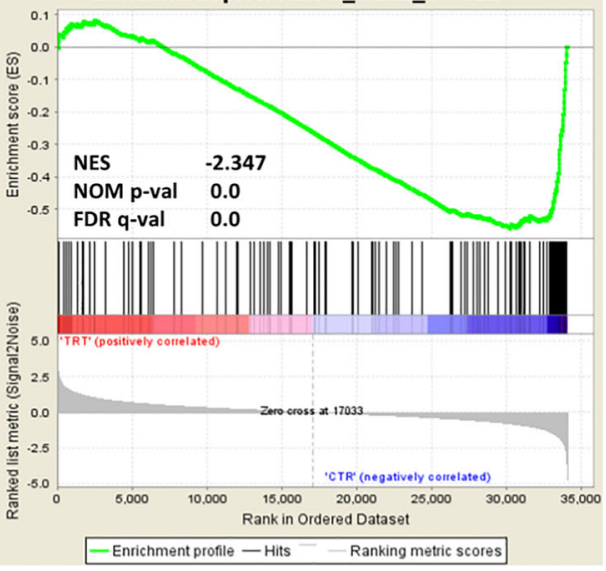

up-regulated, red; right down-regulated, blue). The enrichment score is shown as a green line, and the vertical black bars below the plot indicate the position of cell cycle or DNA replication regulationassociated genes, which are mostly grouped in the fraction of downregulated genes. (Color figure online) 
Fig. 1 continued

B

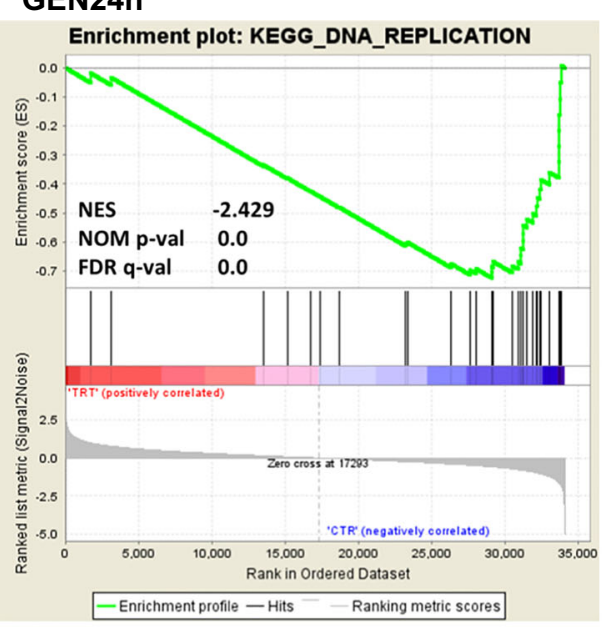

KAEM24h

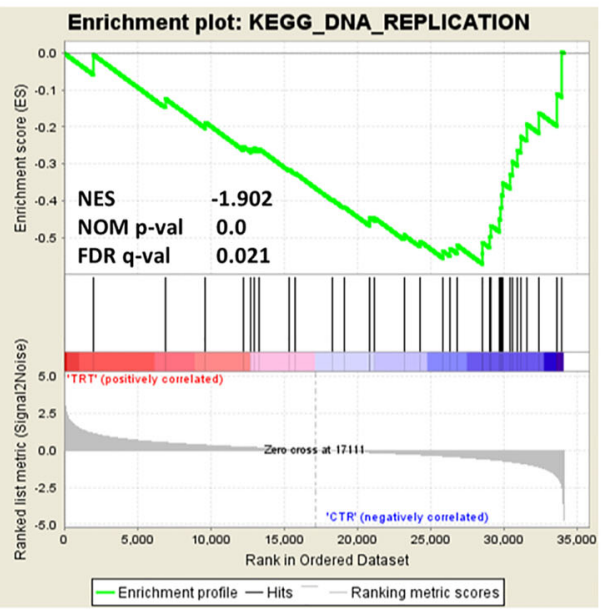

\section{GEN+KAEM24h}

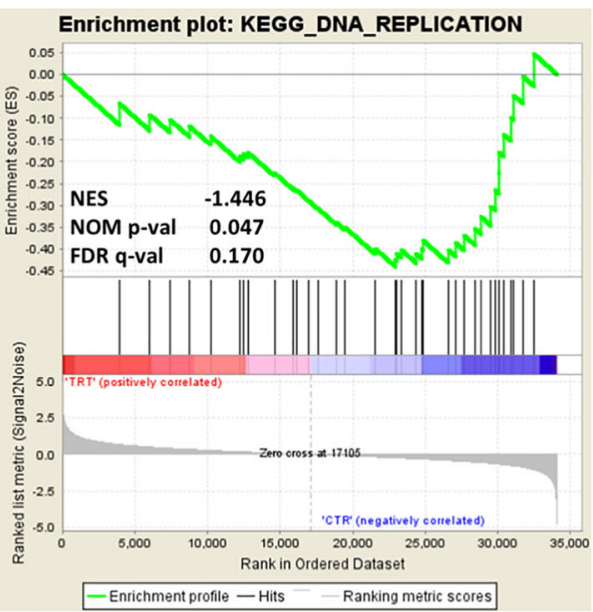

\section{GEN48h}

Enrichment plot: KEGG_DNA_REPLICATION

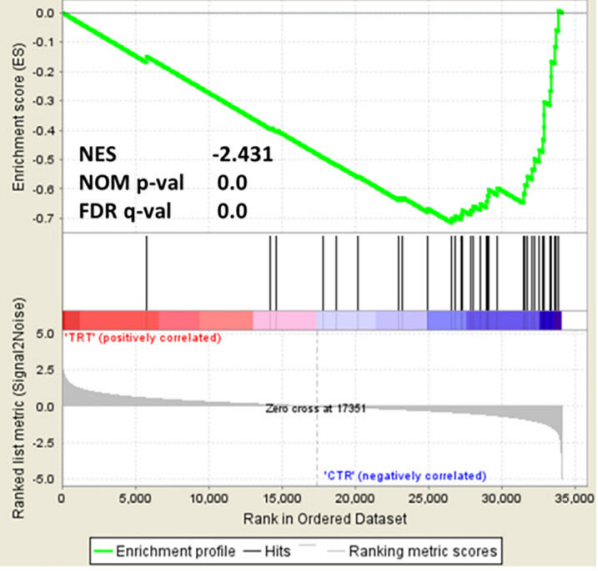

KEAM48h

Enrichment plot: KEGG_DNA_REPLICATION

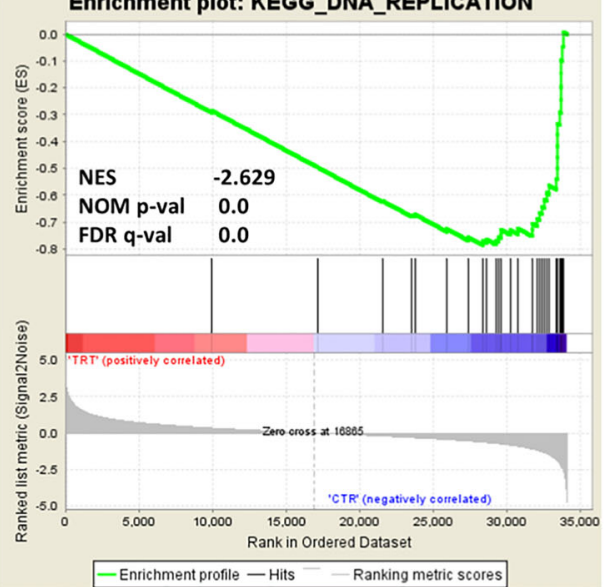

GEN+KEAM48h

Enrichment plot: KEGG_DNA_REPLICATION

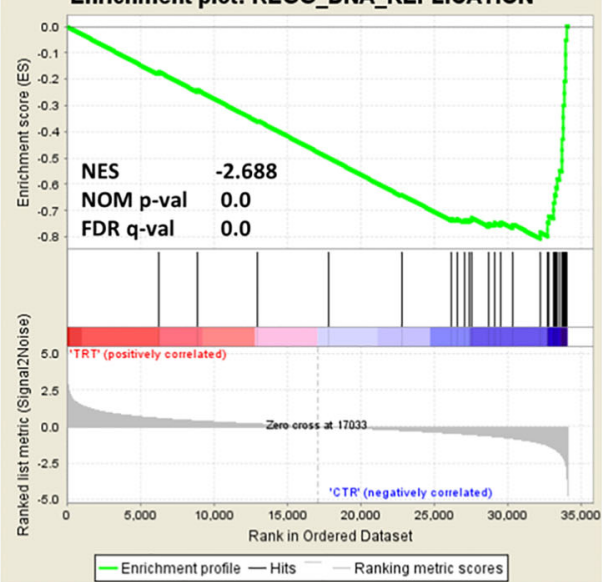

and 72-h incubation periods, respectively. The viability of fibroblasts was additionally assessed with the use of automated cell analyzer system. As seen in Fig. 3, the cell viability did not change remarkably at the tested conditions, although the total cell number was reduced. Moreover, the growth inhibitory effect of genistein was studied in HDFa cells treated with various concentrations (30, 60, and $100 \mu \mathrm{M}$ ) of compound for 7 days (Fig. 4). It 
Fig. 2 GO analysis by 'Cellular Compartment' and 'Biological Processes' category of genes with down-regulated expression upon flavonoids' treatment (100 $\mu \mathrm{M}$ genistein, $100 \mu \mathrm{M}$ kaempferol, and mixture of them of $30 \mu \mathrm{M}$ each, for 24 and $48 \mathrm{~h}$ ) of HDFa cells, with false discovery rate $(F D R)<0.1$, fold change $\geq 1.3$ and below 0.7 , and $P<0.001$. All cell cycle regulation and/or DNA replication relevant cellular compartments and processes are marked in black, while everything else is white

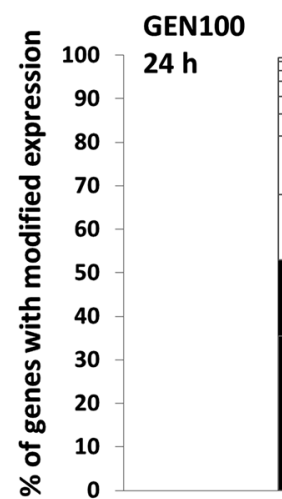

coagulation

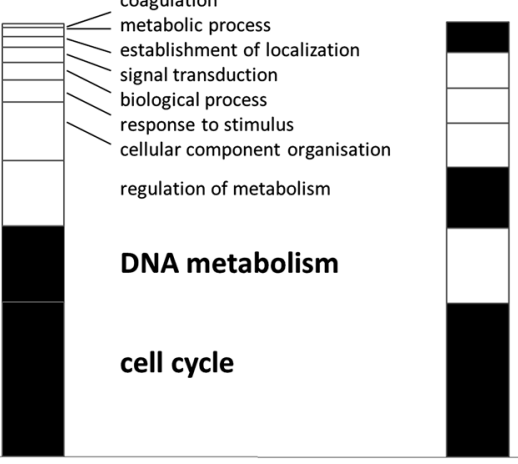

cytoskeletal part

non-membrane bounded organelle cytoplasm

organelle lumen

nuclear protein complex
Biological process

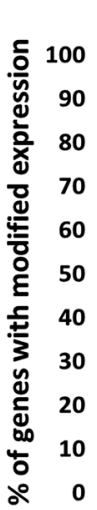

\section{GEN100}

$48 \mathrm{~h}$

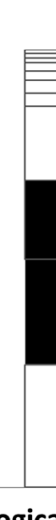

organic substance metabolism response to stimulus establishment of localization extracellular matrix organization coagulation signal transduction

biological process

regulation of biological process

DNA metabolism

cell cycle

cellular component organisation

Cell compartment

nuclear part

membrane bounded organelle

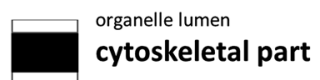

cytoplasm

non-membrane bounded organelle

membrane bounded organelle

nuclear protein complex

nuclear part
Biological process

KAEM100 $24 \mathrm{~h}$

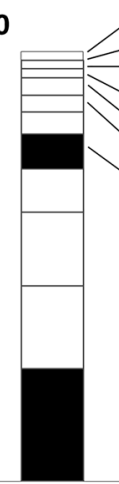

response to stimulus establishment of localization

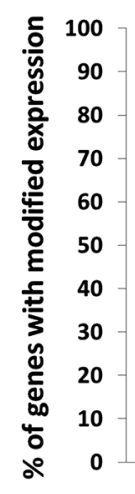
extracellular matrix organization coagulation

signal transduction

biological process

DNA metabolism

organic substance metabolism

regulation of biological process

cellular component organisation

cell cycle

Biological process
Cell compartment

nuclear part

cytoplasm

nuclear protein complex

membrane bounded organelle

cytoskeletal part

Cell compartment

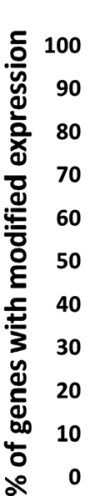

KAEM100 2 viral reproduction $48 \mathrm{~h}$

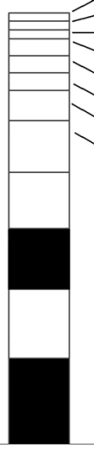
coagulation

organic substance metabolism

response to stimulus

establishment of localization

RNA metabolism

biological process

regulation of biological process

DNA metabolism

cellular component organisation

cell cycle

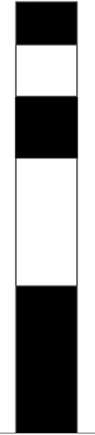

nuclear protein complex cytoplasm

cytoskeletal part

membrane bounded organelle

nuclear part 
Fig. 2 continued
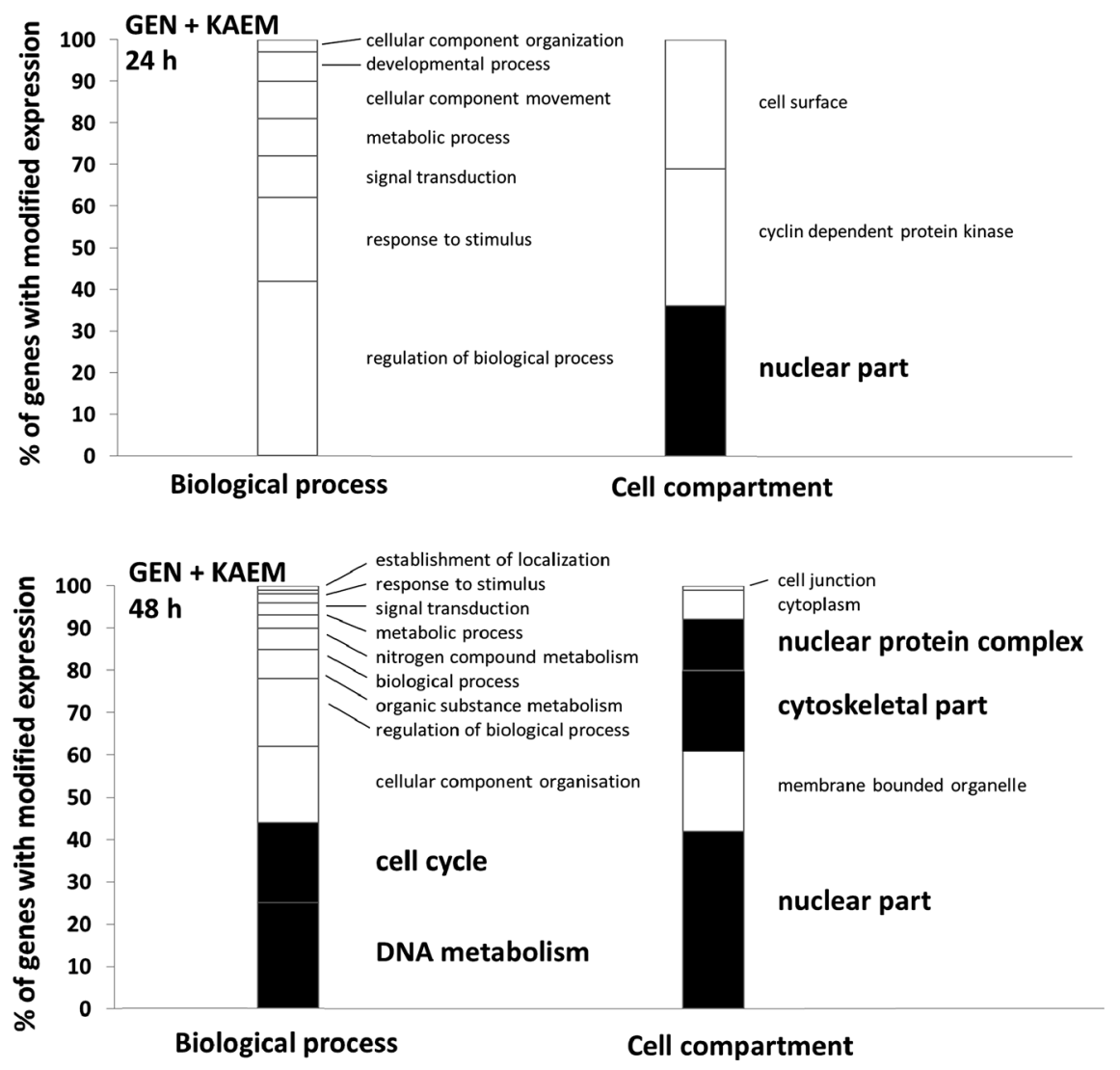

should be noted that the anti-proliferative activity of genistein is concentration dependent.

In addition, the analysis of genistein effect on fibroblast migration by in vitro scratch assay showed acceleration of movement of cells treated with this isoflavone when coupled with control untreated fibroblasts, with time- and dose-dependent alterations (Table 5), thus revealing in vitro wound healing properties of genistein.

Besides, the effect of genistein on cell cycle progression of HDFa fibroblasts after 24, 48, and $72 \mathrm{~h}$ following the addition of this isoflavone was examined. As shown in Fig. 5, in fibroblasts treated with 60 and $100 \mu \mathrm{M}$ genistein, the percentage of G0/G1 cells initially (at $24 \mathrm{~h}$ ) increased in respect to DMSO and $30 \mu \mathrm{M}$ genistein and thereafter gradually decreased after 48 and $72 \mathrm{~h}$; on the contrary, there was induction of untreated cells. As to the $S$ phase, genistein slightly decreased the population of HDFa fibroblasts in a dose-dependent manner, while it induced cell number in the G2/M phase, especially at $72 \mathrm{~h}$. The concentrations greater than $30 \mu \mathrm{M}$ genistein were necessary to alter cell cycle progression, with maximal accumulation of $\mathrm{G} 2 / \mathrm{M}$ cells observed at $100 \mu \mathrm{M}$. However, the increasing percentage of cells in $\mathrm{G} 2 / \mathrm{M}$ stage in response to growing concentration of genistein at $72 \mathrm{~h}$ may also result from anti-proliferative effect of the tested compound (Table 4).

\section{Discussion}

Selected flavonoids were used in cell culture studies to examine their effect on cell cycle and DNA replication. Plant metabolites are compounds met by human cells as humans usually take them with food. Moreover, some of these compounds are either used or proposed for the use in various therapeutic approaches, since they may significantly influence physiology of humans. This is plausible as many plant metabolites have various biological activities, which are, however, rather poorly understood at the molecular level. Therefore, we aimed to investigate mechanisms of influence of these substances on cell division cycle and DNA replication in exemplar eukaryotic system-normal human fibroblasts. We have chosen flavonoids as results of previous studies indicating that they can significantly influence DNA synthesis (see below). The idea to use fibroblasts from a healthy individual arose from the fact that vast majority of studies on effects of flavonoids are performed on cancer cells. What is more, the knowledge regarding the influence of flavonoids on human cell cycle and DNA replication in normal cells, especially in non-neoplastic fibroblasts, is desired as these compounds have extensive medical significance and are used for treatment of some common diseases, due to their proven 
Table 3 Validation of microarray data of selected cell cycle- and/or DNA replication-related genes in HDFa cells by real-time qRT-PCR array

\begin{tabular}{llll}
\hline Cell cycle genes with modulated expression (44) & Protein & FC \pm SD & FC \pm SD (plate
\end{tabular}
(microarray) qRT-PCR)

G1 Phase and G1/S transition (3)

$$
\begin{aligned}
& \text { CDC7 } \\
& \text { CDKN1A (p21) } \\
& \text { CDKN1C (p57) }
\end{aligned}
$$

$S$ Phase and DNA replication (14)

CDT1
FEN1
GINS2
GINS3
GMNN
MCM2
MCM3
MCM4 (CDC21)
MCM5 (CDC46)
MCM6 (Mis5)
MCM7 (CDC47)
MCM8
MCM10
POLE
POLE2
TOP2A

G2 phase and G2/M transition (6) BIRC5 (CPC)

CCNA1
CCNB1
CDK2
PLK1
TPX2

M Phase (3)

\section{CCNB2}

CCNB3

CDC20

Cell cycle checkpoint and cell cycle arrest (14)

CCNA2
CDC45L
CDK2
CDKN1A (p21)
CDKN1C (p57)
CDKN2A (p16)
CDKN2B (p15)
CDKN2C (p18)
CDKN2D (p19)
CHEK1 (CHK1)
CHEK2 (CHK2 / RAD53)
GADD45A (DDIT4)

\section{Cell division cycle 7}

Cyclin-dependent kinase inhibitor $1 \mathrm{~A}$

Cyclin-dependent kinase inhibitor $1 C$

Chromatin licensing and DNA replication factor 1

Flap structure-specific endonuclease 1

GINS complex subunit 2

GINS complex subunit 3

Geminin, DNA replication inhibitor

Minichromosome maintenance complex component 2

Minichromosome maintenance complex component 3

Minichromosome maintenance complex component 4

Minichromosome maintenance complex component 5

Minichromosome maintenance complex component 6

Minichromosome maintenance complex component 7

Minichromosome maintenance complex component 8

Minichromosome maintenance complex component 10

DNA polymerase epsilon subunit 1

DNA polymerase epsilon subunit 2

DNA topoisomerase 2 alpha

Survivin, baculoviral IAP repeat-containing protein 5 (Chromosomal Passenger Complex)

Cyclin A1

Cyclin B1

Cyclin-dependent kinase 2

Polo-like kinase 1

Microtubule-associated targeting protein for Xklp2

Cyclin B2

Cyclin B3

Cell division cycle 20

Cyclin A2

Cell division cycle 45-like

Cyclin-dependent kinase 2

Cyclin-dependent kinase inhibitor $1 \mathrm{~A}$

Cyclin-dependent kinase inhibitor $1 C$

Cyclin-dependent kinase inhibitor $\mathbf{2 A}$

Cyclin-dependent kinase inhibitor $2 B$

Cyclin-dependent kinase inhibitor $2 C$

Cyclin-dependent kinase inhibitor $2 D$

cell cycle checkpoint kinase 1

Cell cycle checkpoint kinase 2

Growth arrest and DNA-damage-inducible 45

(DNA-damage-inducible transcript 1)

Retinoblastoma 1

$$
\begin{array}{ll}
\mathbf{0 . 5 2} \pm \mathbf{0 . 1} & \mathbf{0 . 2 8} \pm \mathbf{0 . 1} \\
2.34 \pm 0.2 & 1.47 \pm 0.2 \\
1.46 \pm 0.3 & 1.30 \pm 0.3
\end{array}
$$

$0.43 \pm 0.1$

$0.43 \pm 0.1$

$0.23 \pm 0.0$

$0.34 \pm 0.0$

$0.19 \pm 0.0$

$0.40 \pm 0.1$

$0.20 \pm 0.0$

$0.62 \pm 0.1$

$0.15 \pm 0.0$

$0.24 \pm 0.0$

$0.20 \pm 0.0$

$0.28 \pm 0.1$

$0.30 \pm 0.0$

$0.23 \pm 0.0$

$0.37 \pm 0.0$

$0.28 \pm 0.0$

$0.27 \pm 0.0$

$0.28 \pm 0.0$

$0.33 \pm 0.0$

$0.54 \pm 0.1$

$0.53 \pm 0.1$

$0.32 \pm 0.0$

$0.69 \pm 0.2$

$0.13 \pm 0.0$

$0.39 \pm 0.1$

$0.10 \pm 0.0$

$0.78 \pm 0.0$

$0.32 \pm 0.2$

$0.42 \pm 0.1$

$0.08 \pm 0.0$

$0.44 \pm 0.0$

$0.21 \pm 0.1$

$0.38 \pm 0.1$

$0.05 \pm 0.0$

$0.33 \pm 0.0$

$0.09 \pm 0.0$

$0.51 \pm 0.1$

$0.10 \pm 0.0$

$0.38 \pm 0.0$

$0.65 \pm 0.2$

$0.42 \pm 0.1$

$0.08 \pm 0.0$

$0.44 \pm 0.1$

$0.11 \pm 0.0$

$0.33 \pm 0.0$

$0.21 \pm 0.0$

$0.44 \pm 0.0$

$0.21 \pm 0.1$

$2.34 \pm 0.2$

$1.47 \pm 0.2$

$1.46 \pm 0.3$

$1.30 \pm 0.3$

$2.04 \pm 0.0 \quad 0.50 \pm 0.1$

$1.34 \pm 0.1 \quad 1.39 \pm 0.1$

$1.23 \pm 0.2 \quad 0.12 \pm 0.0$

$0.70 \pm 0.2 \quad 0.15 \pm 0.0$

$0.38 \pm 0.0 \quad 0.26 \pm 0.0$

$0.67 \pm 0.1 \quad 0.56 \pm 0.0$

$1.55 \pm 0.3 \quad 1.78 \pm 0.6$

$0.61 \pm 0.0 \quad 0.40 \pm 0.1$ 
Table 3 continued

\begin{tabular}{|c|c|c|c|}
\hline Cell cycle genes with modulated expression (44) & Protein & $\begin{array}{l}\text { FC } \pm \text { SD } \\
(\text { microarray })\end{array}$ & $\begin{array}{l}\text { FC } \pm \text { SD (plate } \\
\text { qRT-PCR) }\end{array}$ \\
\hline TP53 (p53) & Tumor protein 53 & $0.59 \pm 0.1$ & $0.74 \pm 0.1$ \\
\hline \multicolumn{4}{|l|}{ Regulation of the cell cycle $(10)$} \\
\hline CCNA1 & Cyclin A1 & $0.78 \pm 0.0$ & $0.32 \pm 0.2$ \\
\hline CCNA2 & Cyclin A2 & $0.44 \pm 0.1$ & $0.11 \pm 0.0$ \\
\hline CCNB1 & Cyclin B1 & $0.42 \pm 0.1$ & $0.08 \pm 0.0$ \\
\hline CCNB2 & Cyclin B2 & $0.51 \pm 0.1$ & $0.10 \pm 0.0$ \\
\hline CDC20 (p55cdc) & Cell division cycle 20 & $0.42 \pm 0.1$ & $0.08 \pm 0.0$ \\
\hline$C D C 45 L$ & Cell division cycle 45-like & $0.33 \pm 0.0$ & $0.21 \pm 0.0$ \\
\hline$C D K 2$ & Cyclin-dependent kinase 2 & $0.44 \pm 0.0$ & $0.21 \pm 0.1$ \\
\hline$E 2 F 2$ & E2F transcription factor & $0.30 \pm 0.1$ & $0.16 \pm 0.0$ \\
\hline GADD45A (DDIT4) & $\begin{array}{l}\text { Growth arrest and DNA-damage-inducible } 45 \\
\text { (DNA-damage-inducible transcript } 1)\end{array}$ & $1.55 \pm 0.3$ & $1.78 \pm 0.6$ \\
\hline$R B 1$ & retinoblastoma 1 & $0.61 \pm 0.0$ & $0.40 \pm 0.1$ \\
\hline \multicolumn{4}{|l|}{ Negative regulation of the cell cycle (4) } \\
\hline$C D C 7$ & Cell division cycle 7 & $0.52 \pm 0.1$ & $0.28 \pm 0.1$ \\
\hline$C D K N 2 B(p 15)$ & Cyclin-dependent kinase inhibitor $2 B$ & $1.34 \pm 0.1$ & $1.39 \pm 0.1$ \\
\hline$C D K N 2 D(p 19)$ & Cyclin-dependent kinase inhibitor $2 D$ & $0.70 \pm 0.2$ & $0.15 \pm 0.0$ \\
\hline TP53 (p53) & tumor protein 53 & $0.59 \pm 0.1$ & $0.74 \pm 0.1$ \\
\hline \multicolumn{4}{|l|}{ Chromosome segregation (3) } \\
\hline BIRC5 (CPC) & $\begin{array}{l}\text { Survivin, baculoviral IAP repeat-containing protein } 5 \\
\text { (Chromosomal Passenger Complex) }\end{array}$ & $0.39 \pm 0.1$ & $0.10 \pm 0.0$ \\
\hline CENPA & Centromere protein A & $0.37 \pm 0.1$ & $0.06 \pm 0.0$ \\
\hline INCENP & Inner centromere protein antigens & $0.67 \pm 0.1$ & $0.15 \pm 0.0$ \\
\hline \multicolumn{4}{|c|}{ Mitotic checkpoint regulators/spindle assembly checkpoint (SAC) (2) } \\
\hline$B U B 1$ & Mitotic checkpoint serine & $0.26 \pm 0.1$ & $0.10 \pm 0.0$ \\
\hline TTK & TTK protein kinase & $0.46 \pm 0.1$ & $0.10 \pm 0.0$ \\
\hline
\end{tabular}

The microarray and real-time qRT-PCR array data represent fold change (FC, greater or equal to 1.3 , and below 0.7 , with $P<0.001)$ averaged values \pm SD from $n \geq 3$ and denote significant differences for samples treated with $100 \mu \mathrm{M}$ genistein against non-treated samples for $24 \mathrm{~h}$, with respect to reference gene GAPDH of constant expression level

The symbols of genes that were down-regulated are bolded in italic and up-regulated normal in italic

Table 4 Cytotoxic activity of genistein expressed as LC25, 50, or 75 index value, i.e., concentration of the tested compound $(\mu \mathrm{M})$ that is lethal to 25,50 , or $75 \%$ of cells in a culture exposed to genistein for 24,48 , and $72 \mathrm{~h}$

\begin{tabular}{lccl}
\hline Time of exposure $(\mathrm{h})$ & $\mathrm{LC}_{25}(\mu \mathrm{M})$ & $\mathrm{LC}_{50}(\mu \mathrm{M})$ & $\mathrm{LC}_{75}(\mu \mathrm{M})$ \\
\hline 24 & $>100$ & $>100$ & $>100$ \\
48 & 59 & $>100$ & $>100$ \\
72 & 41 & 91 & $>100$ \\
\hline
\end{tabular}

ability to inhibit specific enzymes, to simulate some hormones and neurotransmitters, and to scavenge free radicals.

In our study, genistein gave the most spectacular results. It was suggested previously that inhibition of DNA replication by this compound may be due to inactivation of DNA topoisomerases ([3] and references therein).
Moreover, genistein was demonstrated to induce the arrest of the cell cycle in cancer cells [11]. We performed systematic studies to recognize pathways leading to the final effect of cell cycle and DNA replication impairment by genistein and other flavonoids. The transcriptome of the cell line HDFa was profiled with Illumina's Human HT-12 v3 Expression BeadChips. Since genistein gave the most interesting results, this isoflavone was studied in more detail.

We confirmed that genistein influences cell cycle control in the human fibroblast model. More importantly, the results from DNA microarrays were confirmed by an independent, quantitative method, the real-time Reverse Transcription PCR. Both microarray and real-time qRT-PCR analyses indicated that genistein significantly influences expression of many genes involved in cell cycle control at its various stages and DNA replication regulation (Table 3 ). 


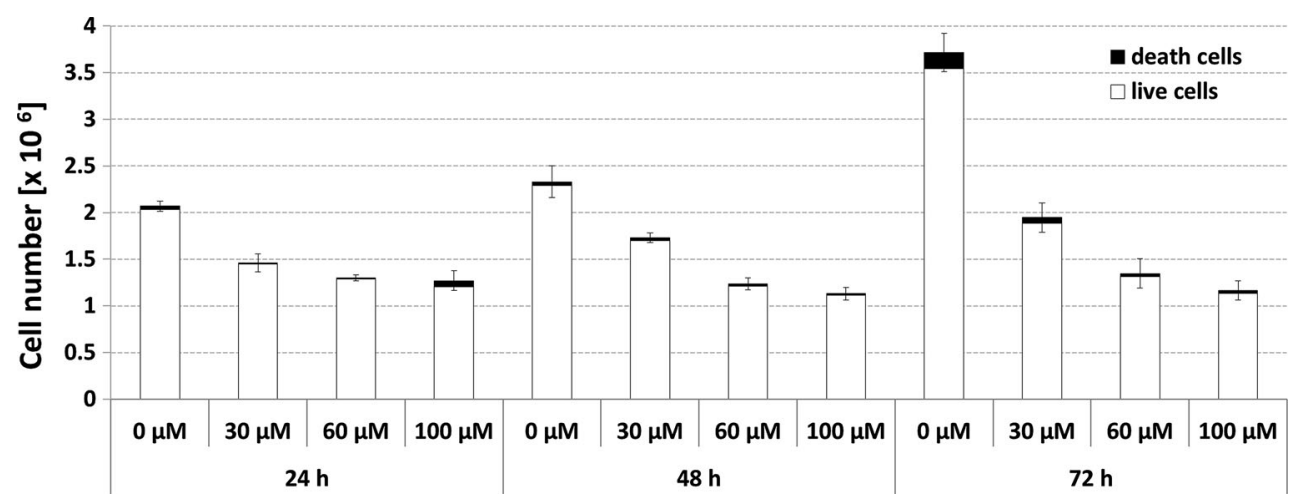

Fig. 3 Determination of count and viability of HDFa cells treated with 30, 60, and $100 \mu \mathrm{M}$ genistein for 24,48 , and $72 \mathrm{~h}$. Data are represented as mean, and bars show SD values of experiments run in triplicate. Cell count test gave statistical differences among experimental groups using one-way ANOVA followed by Tukey's HSD

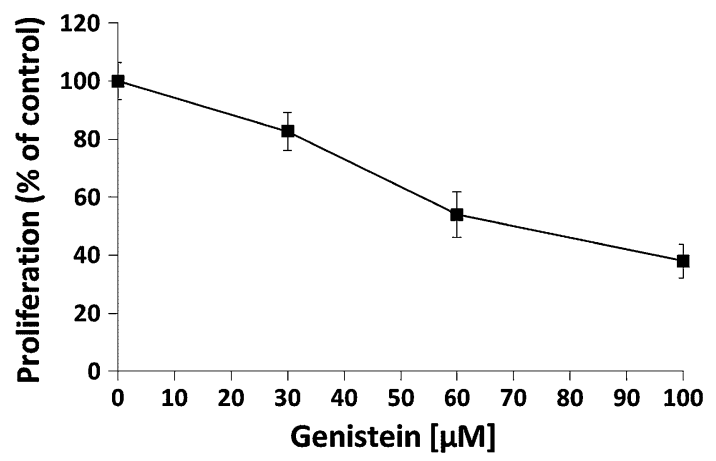

Fig. 4 Effect of genistein on growth of HDFa fibroblasts determined for cultures treated for 7 days with the tested compound of 30,60, and $100 \mu \mathrm{M}$, and calculated as ratio, comparing to the DMSO-treated control. Data are presented as mean values \pm SD from at least triplicate wells and three independent experiments

Genistein is known to inhibit proliferation of human cancer cells [13], which made it a potential anti-cancer therapeutic. Importantly, at concentrations low enough to influence cancer cells, there is only a minor effect on normal cells. As it has attracted attention because of its
Post-Hoc $(P<0.00001)$, while for cell viability, no significant alterations were detected except for cells treated for $72 \mathrm{~h}$ with 60 and $100 \mu \mathrm{M}$ genistein versus control with significance value of $P<0.05$ as determined by one-way ANOVA

beneficial effects on prevention of metabolic disorders related to cardiovascular disease (CVD), obesity, and also diabetes, the side effects and warnings of genistein have ever been considered. Some results could suggest that genistein might impair immunity by its negative effects on mouse thymus gland and various white blood cells [24]. Moreover, in vitro studies have shown genistein to induce apoptosis of testicular cells at certain levels, thus raising concerns about effects it could have on male fertility [25]. However, a recent work indicated that isoflavones had no observable effect in healthy males given isoflavone supplements daily over a 2-month period [26]. Similarly, no significant adverse effects of genistein were observable in studies on two other groups, even when treatment with this isoflavone was as long as 6 or 12 months [27, 28].

The hypothesis on halting of DNA replication through genistein-mediated inhibition of topoisomerase activity, presented for the bacterial model, was also extended to eukaryotic cells [17]. However, our transcriptomic studies indicated that in human cells cultured in the presence of genistein, no alterations in activity of all four genes, TOPA1, TOPA2, TOPB1, and TOPB2, encoding for DNA
Table 5 The effect of genistein on the migration of fibroblasts in a culture supplemented with 30,60 , and $100 \mu \mathrm{M}$ of genistein or $0.05 \%$ DMSO as control

\begin{tabular}{|c|c|c|c|c|c|}
\hline \multirow[t]{2}{*}{ Genistein $(\mu \mathrm{M})$} & \multicolumn{5}{|c|}{ Fibroblast migration ( $\%$ of distance travelled by control cells) } \\
\hline & $0 \mathrm{~h}$ & $6 \mathrm{~h}$ & $12 \mathrm{~h}$ & $18 \mathrm{~h}$ & $24 \mathrm{~h}$ \\
\hline 30 & $121 \pm 13$ & $96 \pm 31$ & $100 \pm 37$ & $99 \pm 41$ & $113 \pm 53$ \\
\hline 60 & $111 \pm 15$ & $107 \pm 28$ & $114 \pm 36$ & $102 \pm 40$ & $115 \pm 53$ \\
\hline 100 & $110 \pm 16$ & $106 \pm 23$ & $115 \pm 31$ & $120 \pm 35$ & $143 \pm 65$ \\
\hline
\end{tabular}

The rate of cell migration was determined for the cells by measuring the distance traveled during the desired time frame of incubation, i.e., at $0,6,12,18$, and $24 \mathrm{~h}$

The data represent averaged values \pm SD of experiments run in triplicate from at least 100 measurements and are denoted as \% of control

Statistical differences among all experimental groups using one-way ANOVA followed by Tukey's HSD Post-Hoc $(P<0.00001)$ were observed 

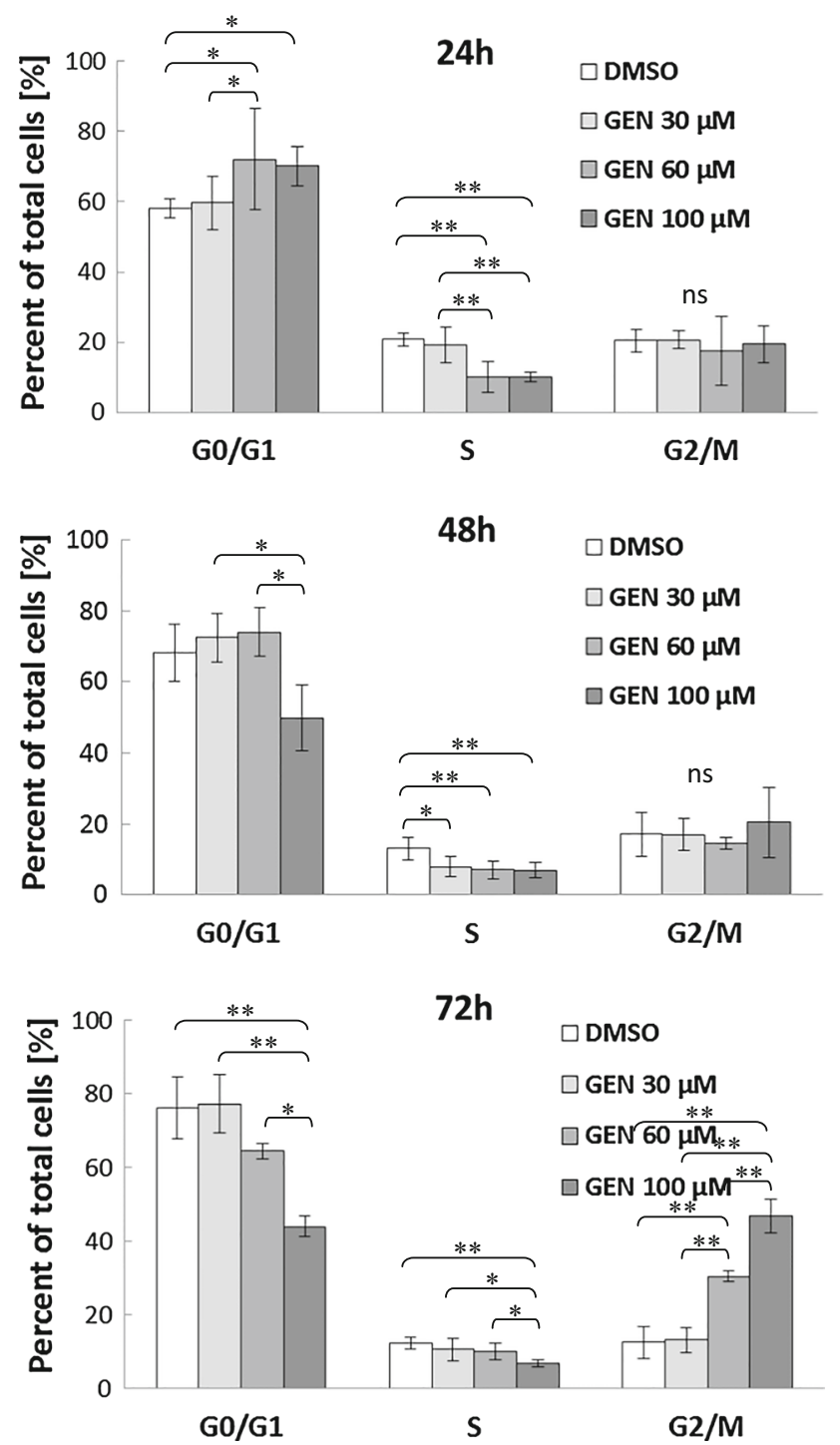

Fig. 5 Effect of genistein on cell cycle progression in $\mathrm{HDFa}$ fibroblasts. After 24, 48, and $72 \mathrm{~h}$ from the addition of 30,60 , or $100 \mu \mathrm{M}$ genistein, the percentage of $\mathrm{G} 0 / \mathrm{G} 1$, S, and $\mathrm{G} 2 / \mathrm{M}$ was calculated. Data are presented as a ratio of total cells counted and represent mean values $\pm \mathrm{SD}$ of at least triplicate experiments. Comparisons among groups were performed using a one-way ANOVA with Tukey HSD Post-Hoc $(* P \leq 0.05$ and $* * P \leq 0.001)$. Ns stands for not significant

topoisomerase were observed. On the contrary, the efficiency of expression of genes coding for MCM2-7 and MCM10 helicases, as well as some other proteins involved in the S phase control, was significantly reduced (Table 3). This may indicate that effects of genistein on DNA replication are not only restricted to its action on topoisomerases, but also include down-regulation of expression of genes required for DNA synthesis. Furthermore, levels of mRNA of genes coding for proteins involved in chromosome segregation were also less abundant in the presence of genistein.

Interestingly, we found that genistein modulates (in most cases down-regulates, but in some up-regulates) expression of a relatively large group of genes, whose products are involved in different phases of the cell cycle (the G1 phase and G1/S phase transition, G2 phase, and G2/M phase transition, $\mathrm{M}$ phase), as well as in regulatory processes, like cell cycle checkpoint and cell cycle arrest, mitotic checkpoint, and spindle assembly checkpoint. Some recent reports also indicated that genistein influences expression of such genes. For example, up-regulation of expression of $p 21$ (CDKN1A) in prostate cancer cells has been described previously [29], and similar results are shown here in normal human fibroblasts. Increased expression of $B D N F$ was detected in genistein-treated hippocampus neuronal cells [30], and decreased levels of the miR-223, a hematopoieticspecific microRNA with crucial function in myeloid lineage development, promoting granulocytic and suppressing erythrocytic differentiation, were found in pancreatic cancer cells in response to this isoflavone [31]. Moreover, in accordance to results presented in this study, genistein was found to induce G2/M cell cycle arrest and apoptosis of human ovarian cancer cells via activation of DNA damage checkpoint pathways [8].

Genistein is known as an inhibitor of various kinases, such as serine, threonine, tyrosine, histidine protein kinases, and the HER-2 kinase [32]. This isoflavone has been shown to inhibit the activation of NF- $\mathrm{\kappa B}$ and Akt signaling pathways, both of which are important for cell survival via maintaining a homeostatic balance between cell survival and apoptosis. Therefore, it is likely that modulation of expression of genes shown in Table 3 is due to genisteinmediated inhibition of particular signal transduction pathways.

In conclusion, our results of transcriptomic analysis supported by real-time qRT-PCR, obtained with the human fibroblasts model, together with results of other researchers who focused on particular genes in other cells, indicate that genistein may regulate cell cycle and DNA replication in human cells due to modulation of expression of a relatively large group of genes whose products are involved in these processes. This regulation may also be accompanied by direct action of genistein on important proteins, like topoisomerases or cyclins; however, this assumption requires further verification.

Acknowledgments This work was supported by National Science Centre (project Grant Nos. UMO-2011/01/B/NZ1/03686, MAESTRO/2011/02/A/NZ1/00009).

Conflict of interest The authors declare that they have no conflict of interest. 
Open Access This article is distributed under the terms of the Creative Commons Attribution 4.0 International License (http:// creativecommons.org/licenses/by/4.0/), which permits unrestricted use, distribution, and reproduction in any medium, provided you give appropriate credit to the original author(s) and the source, provide a link to the Creative Commons license, and indicate if changes were made.

\section{References}

1. Molyneux RJ, Lee ST, Gardner DR, Panter KE, James LF (2007) Phytochemicals: the good, the bad and the ugly? Phytochemistry 68:2973-2985

2. Nakamura Y, Miyoshi N (2010) Electrophiles in foods: the current status of isothiocyanates and their chemical biology. Biosci Biotechnol Biochem 74:242-255

3. Cushnie TP, Lamb AJ (2011) Recent advances in understanding the antibacterial properties of flavonoids. Int J Antimicrob Agents 38:99-107

4. Ferrazzano GF, Amato I, Ingenito A, Zarrelli A, Pinto G, Pollio A (2011) Plant polyphenols and their anti-cariogenic properties: a review. Molecules 16:1486-1507

5. Wegrzyn G, Jakobkiewicz-Banecka J, Gabig-Ciminska M, Piotrowska E, Narajczyk M, Kloska A, Malinowska M, Dziedzic D, Golebiewska I, Moskot M, Wegrzyn A (2010) Genistein: a natural isoflavone with a potential for treatment of genetic diseases. Biochem Soc Trans 38:695-701

6. Messina MJ (2003) Emerging evidence on the role of soy in reducing prostate cancer risk. Nutr Rev 61:117-131

7. Lavigne JA, Takahashi Y, Chandramouli GV, Liu H, Perkins SN, Hursting SD, Wang TT (2008) Concentration-dependent effects of genistein on global gene expression in MCF-7 breast cancer cells: an oligo microarray study. Breast Cancer Res Treat 110:85-98

8. Ouyang G, Yao L, Ruan K, Song G, Mao Y, Bao S (2009) Genistein induces G2/M cell cycle arrest and apoptosis of human ovarian cancer cells via activation of DNA damage checkpoint pathways. Cell Biol Int 33:1237-1244

9. Sarkar FH, Li Y (2002) Mechanisms of cancer chemoprevention by soy isoflavone genistein. Cancer Metastasis Rev 21:265-280

10. Wang SY, Yang KW, Hsu YT, Chang CL, Yang YC (2001) The differential inhibitory effects of genistein on the growth of cervical cancer cells in vitro. Neoplasma 48:227-233

11. Zhang Z, Wang CZ, Du GJ, Qi LW, Calway T, He TC, Du W, Yuan CS (2013) Genistein induces G2/M cell cycle arrest and apoptosis via ATM/p53-dependent pathway in human colon cancer cells. Int J Oncol 43:289-296

12. Ravindranath $M H$, Muthugounder S, Presser N, Viswanathan S (2004) Anticancer therapeutic potential of soy isoflavone, genistein. Adv Exp Med Biol 546:121-165

13. Pavese JM, Farmer RL, Bergan RC (2010) Inhibition of cancer cell invasion and metastasis by genistein. Cancer Metastasis Rev 29:465-482

14. Matsukawa Y, Marui N, Sakai T, Satomi Y, Yoshida M, Matsumoto K, Nishino H, Aoike A (1993) Genistein arrests cell cycle progression at G2-M. Cancer Res 53:1328-1331

15. Mizushina Y, Shiomi K, Kuriyama I, Takahashi Y, Yoshida $\mathrm{H}$ (2013) Inhibitory effects of a major soy isoflavone, genistein, on human DNA topoisomerase II activity and cancer cell proliferation. Int J Oncol 43:1117-1124

16. Wang Q, Wang H, Xie M (2010) Antibacterial mechanism of soybean isoflavone on Staphylococcus aureus. Arch Microbiol 192:893-898
17. Bandele OJ, Osheroff N (2007) Bioflavonoids as poisons of human topoisomerase II alpha and II beta. Biochemistry 46:6097-6108

18. Vermeulen K, Van Bockstaele DR, Berneman ZN (2003) The cell cycle: a review of regulation, deregulation and therapeutic targets in cancer. Cell Prolif 36:131-149

19. Moskot M, Montefusco S, Jakobkiewicz-Banecka J, Mozolewski P, Wegrzyn A, Di Bernardo D, Wegrzyn G, Medina DL, Ballabio A, Gabig-Ciminska M (2014) The phytoestrogen genistein modulates lysosomal metabolism and transcription factor $\mathrm{EB}$ (TFEB) activation. J Biol Chem 289:17054-17069

20. Kloska A, Jakobkiewicz-Banecka J, Narajczyk M, BaneckaMajkutewicz Z, Wegrzyn G (2011) Effects of flavonoids on glycosaminoglycan synthesis: implications for substrate reduction therapy in Sanfilippo disease and other mucopolysaccharidoses. Metab Brain Dis 26:1-8

21. Piotrowska E, Jakobkiewicz-Banecka J, Baranska S, Tylki-Szymanska A, Czartoryska B, Wegrzyn A, Wegrzyn G (2006) Genistein-mediated inhibition of glycosaminoglycan synthesis as a basis for gene expression-targeted isoflavone therapy for mucopolysaccharidoses. Eur J Hum Genet 14:846-852

22. Eden E, Navon R, Steinfeld I, Lipson D, Yakhini Z (2009) GOrilla: a tool for discovery and visualization of enriched GO terms in ranked gene lists. BMC Bioinformatics 10:48

23. Subramanian A, Tamayo P, Mootha VK, Mukherjee S, Ebert BL, Gillette MA, Paulovich A, Pomeroy SL, Golub TR, Lander ES, Mesirov JP (2005) Gene set enrichment analysis: a knowledgebased approach for interpreting genome-wide expression profiles. Proc Natl Acad Sci USA 102:15545-15550

24. Yellayi S, Naaz A, Szewczykowski MA, Sato T, Woods JA, Chang J, Segre M, Allred CD, Helferich WG, Cooke PS (2002) The phytoestrogen genistein induces thymic and immune changes: a human health concern? Proc Natl Acad Sci USA 99:7616-7621

25. Kumi-Diaka J, Rodriguez R, Goudaze G (1998) Influence of genistein $\left(4^{\prime}, 5,7\right.$-trihydroxyisoflavone) on the growth and proliferation of testicular cell lines. Biol Cell 90:349-354

26. Mitchell JH, Cawood E, Kinniburgh D, Provan A, Collins AR, Irvine DS (2001) Effect of a phytoestrogen food supplement on reproductive health in normal males. Clin Sci (Lond) 100:613-618

27. Kim KH, Dodsworth C, Paras A, Burton BK (2013) High dose genistein aglycone therapy is safe in patients with mucopolysaccharidoses involving the central nervous system. Mol Genet Metab 109:382-385

28. de Ruijter J, Valstar MJ, Narajczyk M, Wegrzyn G, Kulik W, Ijlst L, Wagemans T, van der Wal WM, Wijburg FA (2012) Genistein in Sanfilippo disease: a randomized controlled crossover trial. Ann Neurol 71:110-120

29. Seo YJ, Kim BS, Chun SY, Park YK, Kang KS, Kwon TG (2011) Apoptotic effects of genistein, biochanin-A and apigenin on LNCaP and PC- 3 cells by $\mathrm{p} 21$ through transcriptional inhibition of polo-like kinase-1. J Korean Med Sci 26:1489-1494

30. Pan M, Han H, Zhong C, Geng Q (2012) Effects of genistein and daidzein on hippocampus neuronal cell proliferation and BDNF expression in H19-7 neural cell line. J Nutr Health Aging 16:389-394

31. Ma J, Cheng L, Liu H, Zhang J, Shi Y, Zeng F, Miele L, Sarkar FH, Xia J, Wang Z (2013) Genistein down-regulates miR-223 expression in pancreatic cancer cells. Curr Drug Targets 14:1150-1156

32. Banerjee S, Li Y, Wang Z, Sarkar FH (2008) Multi-targeted therapy of cancer by genistein. Cancer Lett 269:226-242 